\title{
Effect of Oil-Droplet Diameter on Lipid Oxidation in O/W Emulsions
}

\author{
Takao Roppongi ${ }^{1}$, Yayoi Miyagawa ${ }^{2}$, Hiroyuki Fujita ${ }^{2}$, and Shuji Adachi ${ }^{2 *}$ \\ ${ }^{1}$ Division of Food Science and Biotechnology, Graduate School of Agriculture, Kyoto University, Sakyo-ku, Kyoto 606-8502, JAPAN \\ ${ }^{2}$ Faculty of Bioenvironmental Sciences, Kyoto University of Advanced Science, Kameoka, Kyoto 621-8555, JAPAN
}

\begin{abstract}
The effect of oil-droplet diameter on lipid oxidation in $\mathrm{O} / \mathrm{W}$ emulsions is unclear, and conflicting results have been reported. These conflictions may be due to different experimental conditions being used, such as the type of oil, the type of emulsifier, temperature, and the range of oil-droplet diameters tested. The method used to evaluate the oxidation could also have varied among studies. In $\mathrm{O} / \mathrm{W}$ emulsions, oxygen dissolved in the aqueous phase is transferred to the oil phase through the oil-water interface and is consumed in the oil phase by oxidation. Therefore, the effect of the oil-droplet diameter on the lipid oxidation rate was evaluated by simultaneously solving the mass balance equations of oxygen and oil in the oil phase. The simulation showed that the oil-droplet diameter does not affect the lipid oxidation rate in $\mathrm{O} /$ W emulsions with oil-droplet diameters on the order of micrometers or less because the oxidation reaction itself is rate-limiting.
\end{abstract}

Key words: lipid oxidation, $\mathrm{O} / \mathrm{W}$ emulsion, oil-droplet diameter, oxidation kinetics, mass transfer

\section{Introduction}

Lipids are one of three major nutrients and are an important energy source for humans. Polyunsaturated fatty acids (PUFAs), such as eicosapentaenoic acid and docosahexaenoic acid (DHA), are examples of lipids with physiological functions that can reduce the risk of cardiovascular disease and prevent cancer. Such functions are called the tertiary functions of foods. Therefore, PUFAs are attracting attention as food ingredients due to these desirable functions ${ }^{1,2}$. However, they are easily oxidized, which subsequently reduces the flavor of foods they are present in and negatively affects the food safety ${ }^{3,4}$. Therefore, to maintain food quality it is important to rationally suppress their oxidation.

Lipid oxidation in bulk systems has been extensively studied, and it is known that many factors, such as lipid type, temperature, and oxygen concentration, affect the oxidation $^{5-7)}$. Lipid oxidation in $\mathrm{O} / \mathrm{W}$ emulsions has also been studied, where the oil-droplet diameter also affects lipid oxidation. Oxygen required for oxidation is supplied from the aqueous phase to the oil phase through the oilwater interface. Sometimes, when the oil-droplet diameter is large, the oxidation is suppressed or delayed due to the resultant small specific surface area of the oil phase. On the other hand, reducing the oil-droplet diameter promotes lipid oxidation because it provides a sufficient supply of oxygen. That is, the mass transfer of oxygen through the oil-water interface is rate-limiting for lipid oxidation when the oil droplets are large, while the oxidation itself is the rate-limiting step when the droplets are small. However, the oil-droplet diameter that determines the rate-limiting step for the oxidation is unclear.

The effect of oil-droplet diameter on lipid oxidation has been experimentally investigated, but conflicting results have been reported. Some studies report that reducing the droplet diameter promotes oxidation ${ }^{8-11)}$, while others state that it delays $i^{12-15)}$. Furthermore, there are reports stating that this parameter has no effect on lipid oxidation ${ }^{16-21)}$. These conflicting results may be due to the difficulty of the experiment, where typically only the oil-droplet size is changed while the other reaction conditions remain unchanged. The method employed for evaluating the oxidation also varies among these studies, which could also contribute to the discrepancies.

In this context, we propose a model to estimate the effect of oil-droplet diameter on lipid oxidation in an $\mathrm{O} / \mathrm{W}$ emulsion. By using the parameters related to lipid oxidation and the mass transfer of oxygen through the oil-water interface, we discuss the oil-droplet diameter at which the effect of oxygen mass transfer through the oil-water interface becomes apparent.

\footnotetext{
*Correspondence to: Shuji Adachi, Faculty of Bioenvironmental Sciences, Kyoto University of Advanced Science, Kameoka, Kyoto 621-8555, JAPAN

E-mail: adachi.shuji@kuas.ac.jp

Accepted May 12, 2021 (received for review April 26, 2021)

Journal of Oleo Science ISSN 1345-8957 print / ISSN 1347-3352 online

http://www.jstage.jst.go.jp/browse/jos/ http://mc.manusriptcentral.com/jjocs

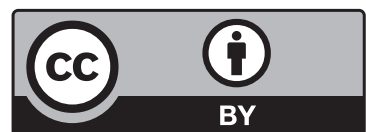




\section{Model}

The entire oxidation process of n-6 PUFAs and the first half of the oxidation process of n-3 PUFAs can be expressed by an autocatalytic equation(Eq. (1)) that depends on the concentrations of unoxidized and oxidized lipids ${ }^{5,22)}$.

$$
\frac{d C_{\mathrm{F}}}{d t}=-k^{\prime} C_{\mathrm{F}}\left(C_{\mathrm{Ft}}-C_{\mathrm{F}}\right)
$$

where $C_{\mathrm{F}}$ is the concentration of unoxidized lipids in the oil droplet, $t$ is the time, $k^{\prime}$ is the oxidation rate constant, and the subscript $t$ indicates the total of unoxidized and oxidized lipids. The oxidation rate constant $k^{\prime}$ depends on the oxygen concentration in the lipid and its dependence is expressed by a Langmuir-Hinshelwood-type equation (Eq. $(2))^{5,7)}$.

$$
k^{\prime}=\frac{k C_{\mathrm{X}}}{K_{\mathrm{X}}+C_{\mathrm{X}}}
$$

where $k$ is the rate constant, $C_{\mathrm{X}}$ is the oxygen concentration in the oil droplet, and $K_{X}$ is the saturation constant of oxygen. From Eqs. (1) and (2), the lipid oxidation rate can then be expressed by Eq. (3).

$$
\frac{d C_{\mathrm{F}}}{d t}=-\frac{k C_{\mathrm{X}}}{K_{\mathrm{X}}+C_{\mathrm{X}}} C_{\mathrm{F}}\left(C_{\mathrm{Ft}}-C_{\mathrm{F}}\right)
$$

The $C_{\mathrm{Ft}}$ value can be calculated by Eq. (4) using the density $\rho$ and the molar mass $M$ of the lipid.

$$
C_{\mathrm{Ft}}=\rho / M
$$

Under the following four assumptions, the increasing rate of oxygen concentration in an oil droplet can be expressed by Eq. (5): (a) oxygen is transferred from the aqueous phase into the oil droplet through an oil-water interface with a mass transfer coefficient of $k_{\mathrm{f}}$; (b) oxygen diffuses quickly in the oil droplet, and the oxygen concentration in oil droplets with a radius of $r_{\mathrm{p}}$ is homogeneous; (c) the oil-droplet diameter does not change during the oxidation $^{13,21)}$; and (d) the stoichiometric coefficient between lipid and oxygen is unity ${ }^{23)}$.

$$
\frac{d C_{\mathrm{X}}}{d t}=-\frac{k C_{\mathrm{X}}}{K_{\mathrm{X}}+C_{\mathrm{X}}} C_{\mathrm{F}}\left(C_{\mathrm{Ft}}-C_{\mathrm{F}}\right)+k_{\mathrm{f}} \frac{3}{r_{\mathrm{p}}}\left(C_{\mathrm{X}}^{*}-C_{\mathrm{X}}\right)
$$

where $C_{\mathrm{X}}^{*}$ is the oxygen concentration in the oil droplet that would be in equilibrium with the oxygen concentration in the aqueous phase. Assuming that the oxygen concentration $C_{\mathrm{Xa}}$ of the aqueous phase is constant due to the sufficiently large volume of the aqueous phase, $C_{\mathrm{X}}^{*}$ is expressed by Eq. (6).

$$
\begin{gathered}
C_{\mathrm{X}}^{*}=K_{\mathrm{d}} C_{\mathrm{Xa}} \\
K_{\mathrm{d}}=\frac{H_{\mathrm{W}}}{H_{\mathrm{L}}}
\end{gathered}
$$

where $H_{\mathrm{W}}$ and $H_{\mathrm{L}}$ are the Henry constants of oxygen to water and lipid, respectively. The concentration of unoxidized lipids $C_{\mathrm{F}}$ is divided by the total concentration of unoxidized and oxidized lipids $C_{\mathrm{Ft}}$, and the oxygen concentration $C_{\mathrm{X}}$ in the oil droplet is divided by the oxygen concentration in the oil droplet that would be in equilibri- um with the aqueous phase $C_{\mathrm{X}}^{*}$. This allows Eqs. (3) and (5) to be rewritten as Eqs. (8) and (9), respectively.

$$
\begin{aligned}
& \frac{d Y}{d \theta}=-\frac{X}{\kappa_{\mathrm{X}}+X} Y(1-Y) \\
& \frac{d X}{d \theta}=-\alpha \frac{X}{\kappa_{\mathrm{X}}+X} Y(1-Y)+\frac{1}{\phi}(1-X)
\end{aligned}
$$

where

$$
\begin{aligned}
& Y=C_{\mathrm{F}} / C_{\mathrm{Ft}} \\
& X=C_{\mathrm{X}} / C_{\mathrm{X}}^{*} \\
& \theta=k C_{\mathrm{Ft}} t \\
& \alpha=C_{\mathrm{Ft}} / C_{\mathrm{X}}^{*} \\
& \kappa_{\mathrm{X}}=K_{\mathrm{X}} / C_{\mathrm{X}}^{*}
\end{aligned}
$$

and

$$
\phi=\frac{k C_{\mathrm{Ft}}}{3 k_{\mathrm{f}} / r_{\mathrm{p}}}
$$

In these equations, $Y$ is the fraction of unoxidized lipid, $X$ is the oxygen saturation in the oil droplet, and $\theta$ is the dimensionless time. $\phi$ is a parameter representing the ratio of the oxidation rate to the oxygen transfer rate, and has the same meaning as the Theile modulus for solid catalysts $^{24)}$. The changes in $Y$ and $X$ with time were calculated by solving Eqs. (8) and (9) using the classical 4th-order Runge-Kutta method and the implicit Euler method at appropriate increments of dimensionless time under the conditions listed in Table 1. Both methods gave practically the same values. The emulsion was assumed to be placed in atmospheric air. The density of DHA methyl ester at $25^{\circ} \mathrm{C}$ was used as the value of DHA ethyl ester, which was unavailable ${ }^{25)}$. The density of DHA ethyl ester at $65^{\circ} \mathrm{C}$ was estimated by extrapolating the temperature dependence of the density of DHA methyl ester ${ }^{25)}$. The $H_{\mathrm{L}}$ values at $25^{\circ} \mathrm{C}$ were estimated from the evaporation enthalpy at $25^{\circ} \mathrm{C}^{26)}$ using Eq. $(16)^{27)}$.

$$
H_{\mathrm{L}} \times 10^{-4}=7.536 \times 10^{-6} \cdot \Delta H_{\text {vap }}+1.0782
$$

The $H_{\mathrm{L}}$ values at $65^{\circ} \mathrm{C}$ were estimated from the temperature dependence of $H_{\mathrm{L}}$ using Eq. $(17)^{27)}$.

$$
\frac{d \ln H_{\mathrm{L}}}{d(1 / T)}=\frac{\Delta H_{\mathrm{sol}}}{R}
$$

where $\Delta H_{\text {sol }}$ is the dissolution enthalpy of oxygen at $25^{\circ} \mathrm{C}^{27)}$. Dividing the reported value of oxygen partial pressure ${ }^{5,7)}$ by $H_{\mathrm{L}}$ gave $K_{\mathrm{X}}$, and dividing the value obtained from the temperature dependence of the concentration-based rate constant $^{5)}$ by $C_{\mathrm{Ft}}$ gave $k$. 
Table 1 Conditions used for the estimations performed with Eqs. (8) and (9).

\begin{tabular}{cccccc}
\hline & & \multicolumn{2}{c}{ Methyl linoleate } & \multicolumn{2}{c}{ DHA ethyl ester } \\
\hline$M$ & {$[\mathrm{~g} / \mathrm{mol}]$} & \multicolumn{2}{c}{294.47} & 256.54 \\
$T$ & {$[\mathrm{C}]$} & 25 & 65 & 25 & 65 \\
$\rho \times 10^{-3}$ & {$\left[\mathrm{~g} / \mathrm{m}^{3}\right]$} & $0.8820^{[25]}$ & $0.8534^{[25]}$ & $0.9162^{[25]}$ & 0.8865 \\
$C_{\mathrm{Ft}}$ & {$\left[\mathrm{mol} / \mathrm{m}^{3}\right]$} & 2995 & 2898 & 2569 & 2486 \\
$\Delta H_{\text {vap }} \times 10^{-3}$ & {$[\mathrm{~J} / \mathrm{mol}]$} & 107.8 & - & 131.8 & - \\
$\Delta H_{\text {sol }} \times 10^{-3}$ & {$[\mathrm{~J} / \mathrm{mol}]$} & -1 & -1 & -1 & -1 \\
$H_{\mathrm{L}} \times 10^{-4}$ & {$\left[\mathrm{~m}^{3} \cdot \mathrm{Pa} / \mathrm{mol}\right]$} & 1.89 & 1.98 & 2.07 & 2.17 \\
$H_{\mathrm{W}} \times 10^{-4}$ & {$\left[\mathrm{~m}^{3} \cdot \mathrm{Pa} / \mathrm{mol}\right]$} & 7.98 & 12.0 & 7.98 & 12.0 \\
$K_{\mathrm{d}}$ & {$[-]$} & 4.22 & 6.05 & 3.86 & 5.53 \\
$C_{\mathrm{Xa}}$ & {$\left[\mathrm{mol} / \mathrm{m}^{3}\right]$} & 0.267 & 0.177 & 0.267 & 0.177 \\
$C_{\mathrm{X}}^{*}$ & {$\left[\mathrm{~mol} / \mathrm{m}^{3}\right]$} & 1.13 & 1.07 & 1.03 & 0.98 \\
$K_{\mathrm{X}} \times 10^{2}$ & {$\left[\mathrm{~mol} / \mathrm{m}^{3}\right]$} & 6.51 & 6.20 & 5.31 & 5.07 \\
$k \times 10^{8}$ & {$\left[\mathrm{~m}^{3} /(\mathrm{mol} \cdot \mathrm{s})\right]$} & 0.182 & 3.31 & 0.721 & 12.9 \\
$k_{\mathrm{f}} \times 10^{6[27]}$ & {$[\mathrm{m} / \mathrm{s}]$} & 1.0 & 1.0 & 1.0 & 1.0 \\
\hline$\alpha \times 10^{-3}$ & {$[-]$} & 2.66 & 2.70 & 2.50 & 2.54 \\
$\kappa_{\mathrm{X}} \times 10^{2}$ & {$[-]$} & 5.78 & 5.78 & 5.17 & 5.17 \\
\hline
\end{tabular}

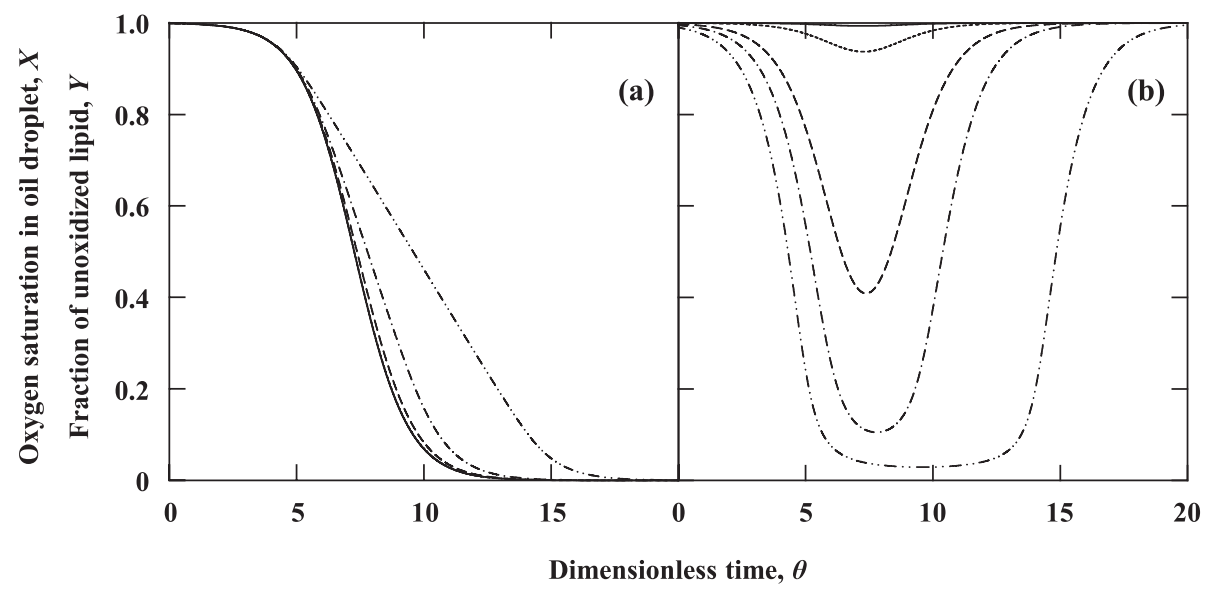

Fig. 1 Changes in (a) the fraction of unoxidized lipid $Y$ and (b) the oxygen saturation $X$ during the oxidation of methyl linoleate at $\phi=1 \times 10^{-5}(-), \phi=1 \times 10^{-4}(---\cdot-\cdot), \phi=1 \times 10^{-3}(---), \phi=2 \times 10^{-3}(--\cdot)$, and $\phi=4 \times 10^{-3}(\cdot-\cdot-\cdot)$.

\section{Results and Discussion}

\subsection{Lipid oxidation under various conditions}

The fraction of unoxidized lipid $Y_{0}$ and the oxygen saturation in the oil droplet $X_{0}$ at the dimensionless time of $\theta=$ 0 were assumed to be 0.999 and 1.0 , respectively. The effect of oil-droplet diameter on the oxidation of methyl linoleate in $\mathrm{O} / \mathrm{W}$ emulsions at $25^{\circ} \mathrm{C}$ was estimated. Figure 1 shows the changes in the fraction of unoxidized lipid $Y$ and the oxygen saturation $X$ for various $\phi$ values over dimensionless time.

The curves for the fraction of unoxidized lipid $Y$ overlapped when $\phi \leq 1 \times 10^{-4}$, but as $\phi$ increased the curves gradually decreased. Oxygen saturation $X$ decreased with dimensionless time except when $\phi=1 \times 10^{-5}$. No significant decrease in oxygen saturation was recognized when $\phi=1$ $\times 10^{-5}$. Additionally, the $X$ value increased again when the lipid was almost oxidized. An increase in $X$ at the end of oxidation such as this indicates that oxygen consumption decreased. These results indicate that an increase in $\phi$, that is, an increase in the oil-droplet radius $r_{\mathrm{p}}$, restricts the mass transfer of oxygen through the oil-water interface to delay lipid oxidation. The dimensionless time required for the fraction of unoxidized lipid $Y$ to reach $0.5,\left(\theta_{0.5}\right)$ was used to reflect the degree of delay in lipid oxidation.

The changes in $Y$ and $X$ for the oil droplets in the emulsions were determined using methyl linoleate with different 


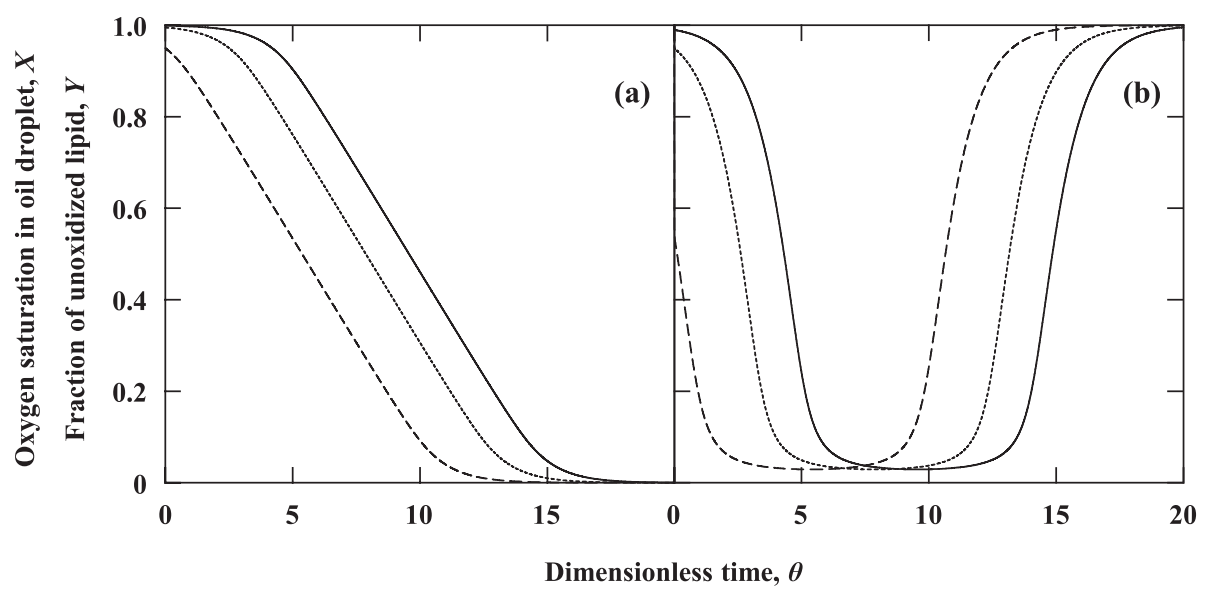

Fig. 2 Changes in (a) the fraction of unoxidized lipid $Y$ and (b) the oxygen saturation $X$ during the oxidation of methyl linoleate with initial fractions of unoxidized lipid $\left(Y_{0}\right)$ of $0.999(-), 0.995(------)$, and $0.950(---)$.

$Y_{0}$ values as the oil phase at the initial oxygen saturation $\left(X_{0}\right)$ of 1 (Fig. 2). As $Y_{0}$ decreased $\theta_{0.5}$ decreased as well, indicating that higher $Y_{0}$ values cause more delay in the oxidation. Moreover, the curves representing the changes in $Y$ almost overlap when translated. This suggests that the initial fraction of unoxidized lipid $Y_{0}$ scarcely affects the oxidation rate, but does only the induction period for the oxidation. The extent of the decrease in oxygen saturation $X$ did not depend on the $Y_{0}$ value, but lower $Y_{0}$ caused $X$ to begin decreasing more rapidly and was linked to the lipid oxidation.

\subsection{Diagram to evaluate factors affecting lipid oxidation}

The effect of the mass transfer rate of oxygen through the oil-water interface on lipid oxidation was assessed by the ratio of $\theta_{0.5}$ at any $\phi$ to that for $\phi \rightarrow 0\left(\theta_{0.5}(\phi \rightarrow 0) / \theta_{0.5}\right)$, which means that the effect of oxygen mass transfer on the oxidation is negligible for infinitely small oil droplets. This index has the same meaning as the effectiveness coefficient for solid catalysts ${ }^{24)}$, and the ratio is equal to 1 when the mass transfer rate of oxygen is sufficiently faster than the lipid oxidation rate. When the oxygen transfer rate limits the oxidation rate, the denominator of the ratio increases. The longer the oxidation is delayed, the smaller the ratio becomes. We then calculated the $\theta_{0.5}(\phi \rightarrow 0) / \theta_{0.5}$ ratio for various $\phi$ values to determine the oil-droplet diameter that affects lipid oxidation. The time at which lipid oxidation was delayed was set to be $\theta_{0.5}(\phi \rightarrow 0) / \theta_{0.5}=0.9$, and the $\phi$ value at that time was estimated.

The relationship between the $\theta_{0.5}(\phi \rightarrow 0) / \theta_{0.5}$ ratio and the $\phi$ values for methyl linoleate and DHA ethyl ester oxidation in the $\mathrm{O} / \mathrm{W}$ emulsion was evaluated under conditions of $25^{\circ} \mathrm{C}, Y_{0}=0.999$, and $X_{0}=1$ (Fig. 3). The $\phi$ for $\theta_{0.5}(\phi \rightarrow 0) /$ $\theta_{0.5}=0.9$ was $2.33 \times 10^{-3}$ for methyl linoleate. Therefore, from Eq. (15), when the oil-droplet diameter is $\geq 2.56 \mathrm{~mm}$, the effect of the oxygen transfer rate at the oil-water interface becomes apparent. The oil-droplet diameter at which

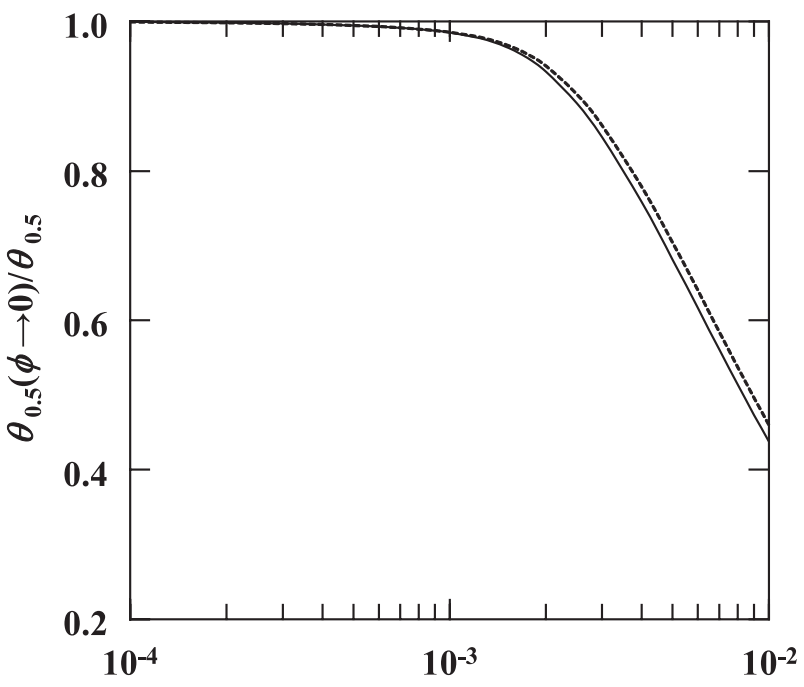

Ratio of oxidation rate to oxygen transfer rate, $\phi$

Fig. 3 Relationships between $\theta_{0.5}(\phi \rightarrow 0) / \theta_{0.5}$ and $\phi$ for the oxidation of methyl linoleate (-) and DHA ethyl ester $(---)$ at $25^{\circ} \mathrm{C}$ in an $\mathrm{O} / \mathrm{W}$ emulsion $(\phi$ represents the ratio of the oxidation rate to the oxygen-transfer rate, as defined by Eq. (15); $\theta 0.5$ $(\phi \rightarrow 0) / \theta_{0.5}$ is the ratio of $\theta_{0.5}$ at any $\phi$ to $\theta_{0.5}$ for $\phi \rightarrow 0)$.

the oxygen transfer rate at the interface began to affect methyl linoleate oxidation (at $65^{\circ} \mathrm{C}$ ) was estimated to be $149 \mu \mathrm{m}$. A similar estimate was made for DHA ethyl ester, which is much easier to oxidize than methyl linoleate, and the oil-droplet diameters were determined to be $807 \mu \mathrm{m}$ and $47 \mu \mathrm{m}$ at $25^{\circ} \mathrm{C}$ and $65^{\circ} \mathrm{C}$, respectively. In every case, the oil-droplet diameters were larger than those found in common food $\mathrm{O} / \mathrm{W}$ emulsions.

The effect of the mass transfer rate of oxygen through the oil-water interface on the DHA ethyl ester oxidation rate at $65^{\circ} \mathrm{C}$ with various $Y_{0}$ values was then investigated 


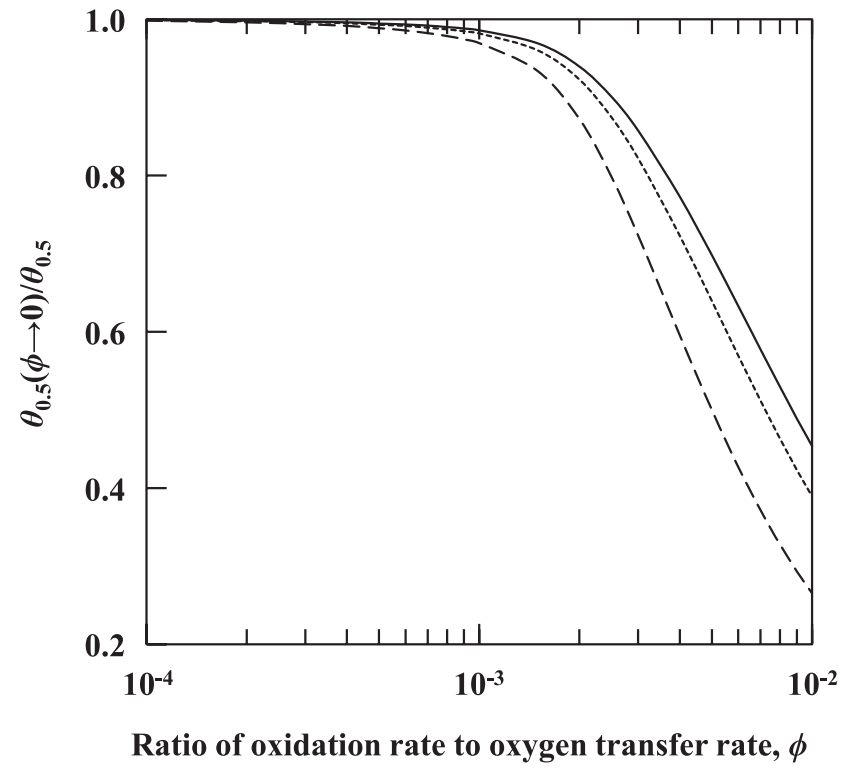

Fig. 4 Relationships between $\theta_{0.5}(\phi \rightarrow 0) / \theta_{0.5}$ and $\phi$ for the oxidation of DHA ethyl esters with different $Y_{0}$ values at $65^{\circ} \mathrm{C}$ in an $\mathrm{O} / \mathrm{W}$ emulsion (the definitions of $\phi$ and $\theta_{0.5}(\phi \rightarrow 0) / \theta_{0.5}$ are the same as those stated in Fig. 3). The initial fractions of unoxidized lipid $\left(Y_{0}\right)$ used are $0.999(-), 0.995(------)$, and 0.950 $(---)$.

(Fig. 4). The $\phi$ values for $\theta_{0.5}(\phi \rightarrow 0) / \theta_{0.5}=0.9$ were estimated to be $2.54 \times 10^{-3}, 2.29 \times 10^{-3}$, and $1.78 \times 10^{-3}$ for DHA ethyl esters with $Y_{0}=0.999,0.990$ and 0.950 , respectively. These $\phi$ values corresponded to oil-droplet diameters of 47 $\mu \mathrm{m}, 43 \mu \mathrm{m}$, and $33 \mu \mathrm{m}$, respectively. These estimates suggest that the mass transfer rate of oxygen through the oil-water interface does not significantly affect the lipid oxidation rate in $\mathrm{O} / \mathrm{W}$ emulsions.

\section{Conclusion}

A model was proposed to evaluate how the mass transfer rate of oxygen through the oil-water interface impacted the lipid oxidation rate in $\mathrm{O} / \mathrm{W}$ emulsions. Using the values reported for the partition coefficient of oxygen in oil, the mass transfer coefficient of oxygen moving through the oilwater interface, and the kinetic parameters for lipid oxidation, we estimated the oil-droplet diameter at which the mass transfer of oxygen through the oil-water interface began to affect the lipid oxidation. The effects of the oil type, temperature, and the initial fraction of unoxidized oil on the diameters were estimated. In every case, the oildroplet diameter was larger than those seen in common $\mathrm{O}$ / $\mathrm{W}$ emulsions. Therefore, it can be concluded that the specific surface area of oil droplets does not affect the oil oxidation rate in common $\mathrm{O} / \mathrm{W}$ emulsions.

\section{Conflict of Interest}

The authors declare that there are no conflicts of interest.

\section{Acknowledgments}

We thank Ms. T. Takahashi for her calculations at the stage of the tentative model. This study was supported by Grant-in-Aid for JSPS Fellows, vide Grant No. JSPS KAKENHI[JP18J01966].

\section{References}

1) Ruxton, C.H.S.; Reed, S.C.; Simpson, M.J.A.; Millington, K.J. The health benefits of omega-3 polyunsaturated fatty acids: A review of the evidence. J. Hum. Nutr. Dietet. 17, 449-459 (2004). doi.org/10.1111/j. 1365-277X.2004.00552.X

2) Tapiero, H.; Ba, G.N.; Couvreur, P.; Tew, K.D. Polyunsaturated fatty acids (PUFA) and eicosanoids in human health and pathologies. Biomed. Pharmacother. 56, 215-222 (2002). doi.org/10.1016/S0753-3322 (02) 00193-2

3) Warner, K.; Evans, C.D.; List, G.R.; Dupuy, H.P.; Wadsworth, J.I.; Goheen, G.E. Flavor score correlation with pentanal and hexanal contents of vegetable oil. $J$. Am. Oil Chem. Soc. 55, 252-256 (1978). doi.org/10. 1007/BF02676935

4) Esterbauer, H.; Schaur, R.J.; Zollner, H. Chemistry and biochemistry of 4-hydroxynonenal, malonaldehyde and related aldehydes. Free Radic. Boil. Med. 11, 81128 (1991). doi.org/10.1016/0891-5849 (91)90192-6

5) Adachi, S.; Ishiguro, T.; Matsuno, R. Autoxidation kinetics for fatty acids and their esters. J. Am. Oil Chem. Soc. 72, 547-551(1995). doi.org/10.1007/BF 02638855

6) Yoshii, H.; Furuta, T.; Itoh, T.; Yoshimura, K.; Misawa, Y.; Hata, N.; Kobayashi, H.; Linko, Y.Y.; Linko, P. Kinetic analysis of the autoxidation of ethyl eicosapentaenoate at different oxygen levels. Biosci. Biotechnol. Biochem. 63, 662-665(1999). doi.org/10.1271/bbb. 63.662

7) Ma, T.; Kobayashi, T.; Adachi, S. Kinetics of oxidation of different depths of methyl linoleate in bulk phase. Food Sci. Technol. Res. 20, 183-187(2014). doi.org/ 10.3136/fstr.20.183

8) Gohtani, S.; Sirendi, M.; Yamamoto, N.; Kajikawa, K.; Yamano, Y. Effect of droplet size on oxidation of docosahexaenoic acid in emulsion system. J. Dispers. Sci. Technol. 20, 1319-1325 (1999). doi.org/10.1080/ 01932699908943855

9) Lethuaut, L.; Métro, F.; Genot, C. Effect of droplet size 
on lipid oxidation rates of oil-in-water emulsions stabilized by protein. J. Am. Oil Chem. Soc. 79, 425 (2002) . doi.org/10.1007/s11746-002-0500-Z

10) Neves, M.A.; Wang, Z.; Kobayashi, I.; Nakajima, M. Assessment of oxidative stability in fish oil-in-water emulsions: Effect of emulsification process, droplet size and storage temperature. J. Food Process. Eng. 40, e12316 (2017). doi.org/10.1111/jfpe.12316

11) Li, P.; McClements, D.J.; Decker, E.A. Application of flow cytometry as novel technology in studying the effect of droplet size on lipid oxidation in oil-in-water emulsions. J. Agric. Food Chem. 68, 567-573(2020). doi.org/10.1021/acs.jafc.9b04956

12) Nakaya, K.; Ushio, H.; Matsukawa, S.; Shimizu, M.; Ohshima, T. Effects of droplet size on the oxidative stability of oil-in-water emulsions. Lipids 40, 501-507 (2005) . doi.org/10.1007/s11745-005-1410-4

13) Imai, H.; Maeda, T.; Shima, M.; Adachi, S. Oxidation of methyl linoleate in oil-in-water micro- and nanoemulsion systems. J. Am. Oil Chem. Soc. 85, 809-815 (2008) . doi.org/10.1007/s11746-008-1257-3

14) Ries, D.; Ye, A.; Haisman, D.; Singh, H. Antioxidant properties of caseins and whey proteins in model oilin-water emulsions. Int. Dairy J. 20, 72-78(2010). doi.org/10.1016/j.idairyj.2009.09.001

15) Nguyen, H.H.; Choi, K.-O.; Kim, D.E.; Kang, W.-S.; Ko, S. Improvement of oxidative stability of rice bran oil emulsion by controlling droplet size. J. Food Process. Preserv. 37, 139-151 (2013). doi.org/10.1111/j.17454549.2011.00633.x

16) Roozen, J.P.; Frankel, E.N.; Kinsella, J.E. Enzymic and autoxidation of lipids in low fat foods: Model of linoleic acid in emulsified hexadecane. Food Chem. 50, 33-38 (1994) . doi.org/10.1016/0308-8146 (94)90089-2

17) Osborn, H.T.; Akoh, C.C. Effect of emulsifier type, droplet size, and oil concentration on lipid oxidation in structured lipid-based oil-in-water emulsions. Food Chem. 84, 451-456 (2004).

18) Paraskevopoulou, D.; Boskou, D.; Paraskevopoulou, A. Oxidative stability of olive oil-lemon juice salad dressings stabilized with polysaccharides. Food Chem. 101, 1197-1204 (2007). doi.org/10.1016/j.foodchem. 2006.03 .022

19) Dimakou, C.P.; Kiokias, S.N.; Tsaprouni, I.V.; Oreopou- lou, V. Effect of processing and storage parameters on the oxidative deterioration of oil-in-water emulsions. Food Biophys. 2, 38(2007). doi.org/10.1007/s11483007-9027-6

20) Kiokias, S.; Dimakou, C.; Oreopoulou, V. Effect of heat treatment and droplet size on the oxidative stability of whey protein emulsions. Food Chem. 105, 94-100 (2007). doi.org/10.1016/j.foodchem.2007.03.053

21) Ma, T.; Kobayashi, T.; Adachi, S. Effect of droplet size on autoxidation rates of methyl linoleate and $\alpha$-linolenate in an oil-in-water emulsion. J. Oleo Sci. 62, 1003-1008 (2013). doi.org/10.5650/jos.62.1003

22) Özilgen, S.; Özilgen, M. Kinetic model of lipid oxidation in foods. J. Food Sci. 55, 498(1990). doi.org/10. 1111/j.1365-2621.1990.tb06795.x

23) Adachi, S.; Ishiguro, T.; Matsuno, R. Thermal analysis of autoxidation of ethyl esters of n-3 and n- 6 fatty acids. Food Sci. Technol. Int. 1, 1-4(1995). doi.org/10. 3136/fsti9596t9798.1.1

24) Levenspiel, O. Chemical Reaction Engineering, $2^{\text {nd }}$ ed., John Wiley \& Sons, Toronto, Canada, Chapter 14 (1972).

25) Knothe, G.; Steidley, K.R. A comprehensive evaluation of the density of neat fatty acids and esters. J. Am. Oil Chem. Soc. 91, 1711-1722(2014). doi.org/10.1007/ s11746-014-2519-x

26) Lipkind, D.; Kapustin, Y.; Umnahanant, P.; Chickos, J.S. The vaporization enthalpies and vapor pressures of a series of unsaturated fatty acid methyl esters by correlation gas chromatography. Thermochim. Acta 456, 94-101 (2007). doi.org/10.1016/j.tca.2007.02.008

27) Roppongi, T.; Mizuno, N.; Miyagawa, Y.; Kobayashi, T.; Nakagawa, K.; Adachi, S. Solubility and mass transfer coefficient of oxygen through gas- and water-lipid interfaces. J. Food Sci. 86, 867-873(2021). doi.org/10. $1111 / 1750-3841.15641$

CC BY 4.0 (Attribution 4.0 International). This license allows users to share and adapt an article, even commercially, as long as appropriate credit is given. That is, this license lets others copy, distribute, remix, and build upon the Article, even commercially, provided the original source and Authors are credited. 